
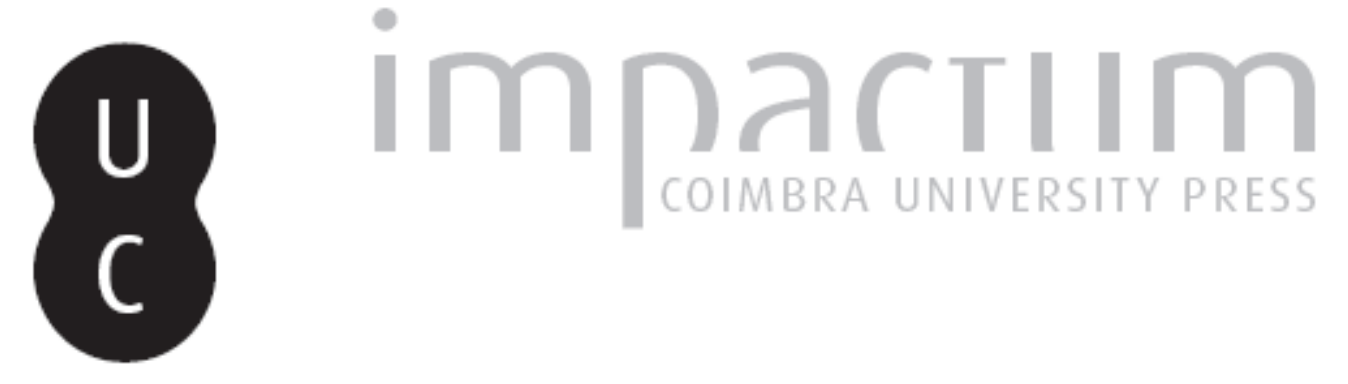

\title{
Eros, paideia e Filosofia: Sócrates entre Diotima e Alcibíades
}

\section{Autor(es): $\quad$ Ferrari, Franco}

Publicado por: Annablume Clássica; Imprensa da Universidade de Coimbra

URL persistente:

URI:http://hdl.handle.net/10316.2/24306

DOI:

DOI:http://dx.doi.org/10.14195/1984-249X_9_6

Accessed : $\quad$ 26-Apr-2023 12:47:23

A navegação consulta e descarregamento dos títulos inseridos nas Bibliotecas Digitais UC Digitalis, UC Pombalina e UC Impactum, pressupõem a aceitação plena e sem reservas dos Termos e Condições de Uso destas Bibliotecas Digitais, disponíveis em https://digitalis.uc.pt/pt-pt/termos.

Conforme exposto nos referidos Termos e Condições de Uso, o descarregamento de títulos de acesso restrito requer uma licença válida de autorização devendo o utilizador aceder ao(s) documento(s) a partir de um endereço de IP da instituição detentora da supramencionada licença.

Ao utilizador é apenas permitido o descarregamento para uso pessoal, pelo que o emprego do(s) título(s) descarregado(s) para outro fim, designadamente comercial, carece de autorização do respetivo autor ou editor da obra.

Na medida em que todas as obras da UC Digitalis se encontram protegidas pelo Código do Direito de Autor e Direitos Conexos e demais legislação aplicável, toda a cópia, parcial ou total, deste documento, nos casos em que é legalmente admitida, deverá conter ou fazer-se acompanhar por este aviso.

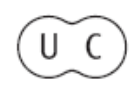




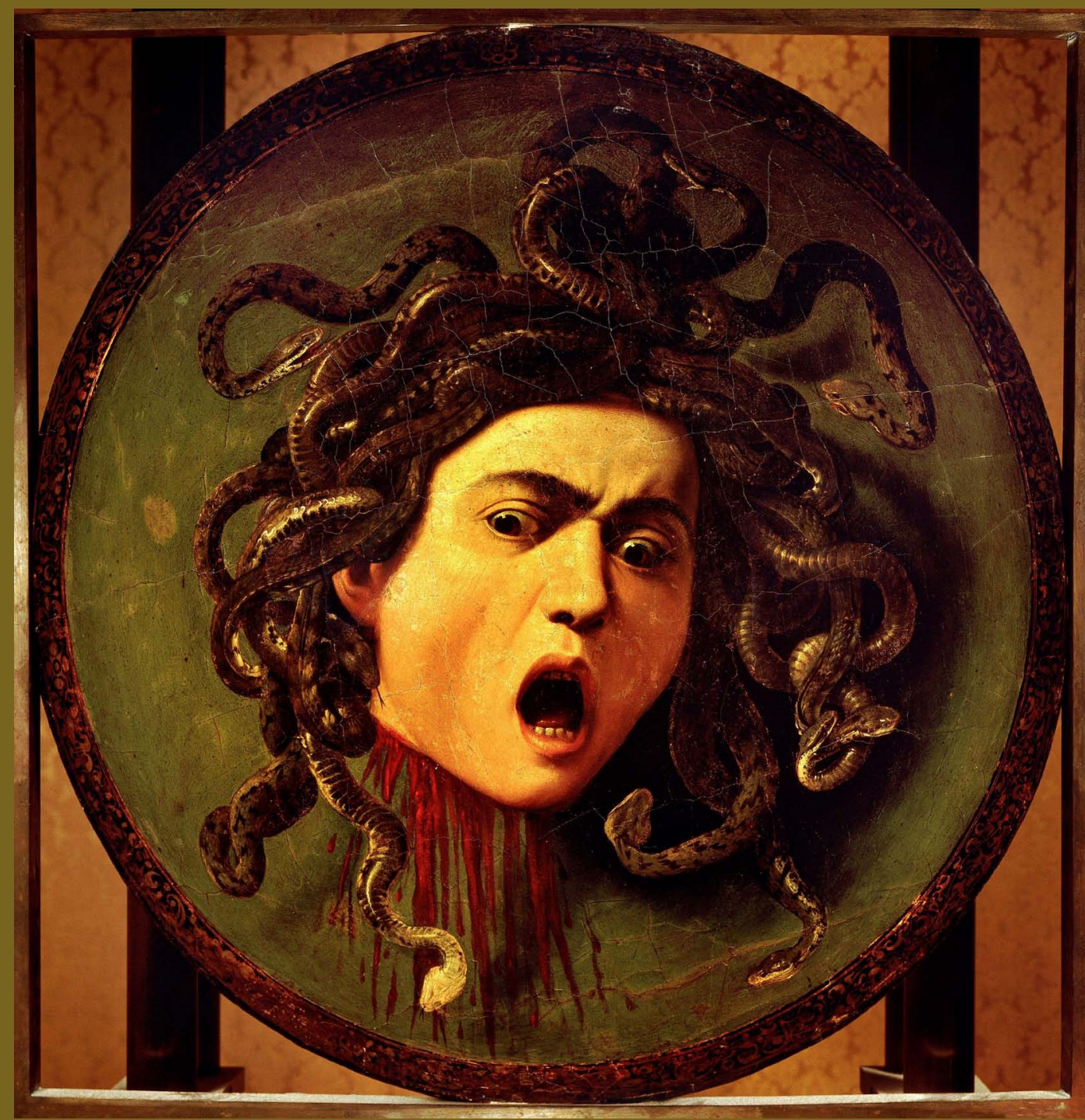

\section{R E V I S T A}
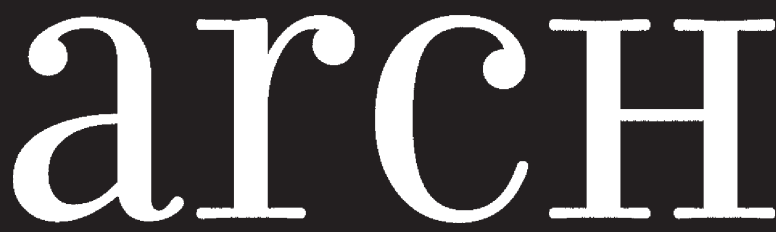
AS ORIGENS DO PENSAMENTO OCIDENTAL

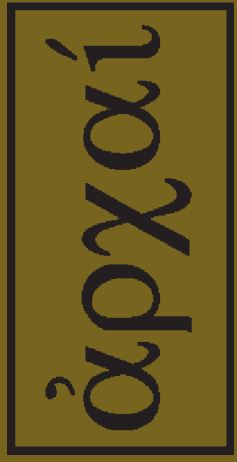

ARCHAI JOURNAL: ON THE ORIGINS OF WESTERN THOUGHT
arcHaI

arementam

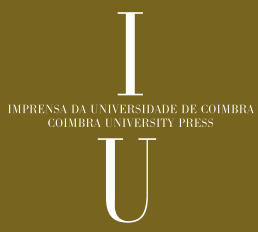

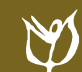

NNN 


\section{EROS, PAIDEIA E FILOSOFIA: SÓCRATES ENTRE DIOTIMA E ALCIBÍADES}

FERRARI, F. (2012). “Eros, Paideia e Filosofia: Sócrates entre Diotima e Alcibíades". Archai n. 9, jul-dez 2012, pp. 65-116.

RESUMO: 0 propósito deste ensaio é o de investigar as razões pelas quais a educação de Alcibíades por Sócrates não é tão exitosa quanto a educação de Sócrates por Diotima. Em outras palavras: qual é o motivo da derrota de Sócrates enquanto educador? Segundo a minha interpretação, enquanto Sócrates aprende de Diotima a scala amoris com a separação ontológica entre entidades materiais e imateriais, isto é, ideais, Alcibíades não recebe esta mesma teoria de Sócrates. A falta deste conhecimento (isto é, dos princípios metafísicos do platonismo) é a razão pela qual Alcibíades pode propor a Sócrates a troca da verdade (isto é, da verdadeira virtude) pela opinião (a beleza corporal).

PALAVRAS-CHAVE: Sócrates, Alcebiades, paideia, amor, relação assimétrica

ABSTRACT: The aim of this essay is to investigate the reasons because the education of Alcibiades by Socrates is not successfull as the education of Socrates by Diotima. In other words: what is the reason of Socrates' failure as teacher? According to my interpretation, whereas Socrates knows from Diotima the scala amoris with the ontological separation between material and immaterial i.e. ideal entities, Alcibiades cannot know from Socrates this theory. The failure of this knowledge (i.e. of the metaphysical principles of platonism) is the reason because Alcibiades can propose to Socrates to change the truth (i.e. the real virtue) with the opinion (the corporal beauty).

KEY-WORDS: Socrates, Alcibiades, paideia, love, asimmetrical relationship.
Franco Ferrari *

* Professor Titular da Università degli Studi di Salerno, Itália.

1. Sobre a influência deste texto, veja-se o que diz Sier (1997, p. 147), com as oportunas indicações bibliográficas.

2. A este propósito escrevia Wilamowitz (1919, p. 151).
1. A concepção platônica do Eros exerceu uma forte influência sobre todo o nosso pensamento europeu, chegando em certos momentos - por exemplo, no âmbito do neoplatonismo renascentista - a ser identificada com a própria filosofia de Platão. A scala amoris descrita por Diotima representa um dos textos mais influentes de toda a literatura antiga e o seu Nachleben envolveu, entre outros, a mística medieval e o Renascimento e inspirou pensadores como Hölderlin ${ }^{1}$ (1997). Apesar desta indubitável popularidade não se pode dizer que a erótica platônica se mostre imediatamente reconduzível à perceção que nós modernos costumamos sentir quando falamos de "amor".

De facto, e muitos estudiosos não deixaram de o constatar, o Eros platônico parece configurar-se como uma relação de natureza assimétrica em que a componente da reciprocidade se mostra ausente ou então marginal. Este aspecto é ulteriormente reforçado pelo fato de Eros, pelo menos nas suas formas mais elevadas, se dirigir a realidades impessoais, como o Belo, o Bem ou a sophia, que evidentemente não podem resultar agentes da tensão erótica de que são objeto ${ }^{2}$. Em poucas palavras, a erótica platônica parece bastante indiferente ao Lebenshorizont des Individuums, ou seja, às motivações e à esfera pessoal e individual. 
Tanto a natureza unidirecional e assimétrica do Eros platônico quanto a sua orientação prevalecente para realidades inanimadas ${ }^{3}$ revelaram-se, de certa forma, problemáticas, suscitando o interesse dos comentadores. 0 caso mais célebre é decerto o de Gregory Vlastos (1973), que acusou o Eros socrático de failure of love, de falta de amor, para não dizer de frigidez ${ }^{4}$. 0 resultado nefasto da educação de Alcibíades por parte de Sócrates, tal como é descrito na última parte do Banquete, seria em certo sentido a consequência inevitável deste excesso de impersonalidade. Também se observou que, quando o impulso erótico se dirige para um indivíduo, acontece de maneira instrumental, pois a beleza individual pode ativar uma energia canalizada posteriormente para a esfera impessoal das ideias ${ }^{5}$.

Os diálogos que tratam de maneira direta 0 tema do amor são três: o Lísis, que tem por objeto a natureza da philia, ou melhor, o fenómeno da atração que se verifica quando alguém ou algo é "querido" (philos) para alguém, ou quando alguém ama, ou seja, é philos de, algo ou alguém; o Fedro, com a célebre sequência dos discursos em encómio a Eros; e o Banquete, que se dedica precisamente às reflexões contidas neste contributo. Na verdade, como demonstrou de modo convincente Charles Kahn, o Lísis e o Banquete desenvolvem uma concepção muito semelhante, e o primeiro diálogo parece efetivamente representar a antecipação das teses apresentadas de forma mais articulada no segundo ${ }^{6}$.

Aqui, gostaria de me concentrar em particular sobre os aspectos formais da concepção do Eros que se retiram da relação entre os discursos de Sócrates, que se refere ao conteúdo do ensinamento da sacerdotisa Diotima, e o discurso de Alcibíades, que não fala diretamente de Eros, mas sim de Sócrates, que representa evidentemente a personificação de Eros $^{7}$. Como é natural, cada interpretação do Banquete exigiria um exame cuidadoso de todos os sete discursos sobre Eros declamados pelos protagonistas do banquete em honra da vitória de Ágaton na competição trágica de 416, mas não há dúvida de que, devido às personagens que as pronunciam, as últimas duas intervenções ocupam um lugar privilegiado: uma sacerdotisa e um ambicioso e brithante homem político, ligado intimamente a Sócrates e ao seu círculo intelectual.

2. Na verdade, também as palavras com as quais Sócrates comenta o discurso de Ágaton (199 C-201 C), antes de passar a palavra a Diotima, exprimem um ponto de vista muito significativo, até porque depende do ensinamento que Sócrates recebera de Diotima muitos anos antes. Ele submete ao procedimento do elenchos a tese de Ágaton, segundo a qual Eros é um deus e como tal é autossuficiente. $\mathrm{Na}$ realidade, tudo se passa de maneira diversa, porque Eros não é autossuficiente relativamente ao bem (agathon) e ao belo (kalon), mas pelo contrário caracteriza-se pela condição de falta (endeia) daquilo que deseja. Se Eros, como se mostra pela intervenção de Sócrates-Diotima, representa a condição do desejo (epithymia), a tese que Platão parece querer veicular reduz-se ao princípio geral segundo o qual cada desejo (erótico) pressupõe que o agente perceba uma discrepância entre o que ele é (ou tem) e o que reconheceu como digno de valor. A estratégia de subtração da natureza divina a Eros encontra uma expressão hipostática na atribuição a ele da qualificação de daimon megas (202 D-E), de grande daimon, uma entidade que ocupa um lugar intermédio entre os deuses (que estão em perpétua posse do bem e do belo) e os homens (que, ao invés, resultam estar privados de ambas as qualidades) ${ }^{8}$.

$\mathrm{Na}$ verdade, como demonstrou de maneira convincente Filip Karfik (2007), os deuses, isto é, os seres imortais de que fala Diotima, não são senão as entidades imutáveis e eternas da metafísica de Platão, ou seja, as ideias, enquanto que os mortais deveriam representar a realidade física e material $(207 \mathrm{D}-208 \mathrm{~A})^{9}$. Mas se isto é verdadeiro, então a característica intermediária de Eros não se esgota em nível epistémico, mas abrange também a esfera propriamente ontológica.

Em qualquer caso, não há dúvida de que a descrição de Eros deve referir-se imediatamente à condição do filósofo e de Sócrates, que representa a personificação da filosofia ${ }^{10}$. Para Platão a filosofia apresenta uma natureza intrinsecamente erótica (e 'demoníaca'), cujos traços distintivos são representados por uma condição de falta, ou seja, de não
3. Em Eth. Nic. VIII 2. 1155b278 Aristóteles negava que se pudesse considerar philia a ligação para realidades inanimadas (to apsycha). Todavia, a sua doutrina de Metaph. XII relativa à atração do primeiro motor imóvel, que move enquanto objeto de amor (hos eromenon), parece retomar muitos motivos contidos no Banquete: cf. para esta hipótese Chang (2002, p. 431-46).

4. Vale a pena consultar também a brilhante discussão contida em Nussbaum (1996, p. 332 segs).

5. Um quadro inteligente destes problemas encontra-se em Centrone (2009, p. 33-49).

6. Veja-se Kahn $(2008$, p. 277 86), que propõe uma leitura proléptica do Lísis (e de todos os chamados diálogos socráticos), que permite atenuar, chegando a eliminar a aparente natureza aporética deste escrito. Sobre a presença no Lísis de temáticas de ordem epistemológica não diferentes daquelas contidas no Banquete remeto para o meu artigo (2002)

7. Como Marsílio Ficino já tinha afirmado. Veja-se, a esse propósito, Dixsaut (2003, p. 219, nota 80). Sobre a interpretação de Ficino do Banquete, veja-se Robinson (2007, p. 312-25).

8. Esta Absetzung als theos de Eros explica a circunstância de que o fim do homem, de que Eros constitui a expressão metafórica, seja colocado na homoiosis theó, quer dizer, na assimilação a deus, que representa uma condição para a qual o homem tende, mas que ele não possui naturalmente: Sier (1997, p. 37).

9. Havlicek \& Cajthaml (p. 14763, espec. 152-53).

10. Sobre a natureza "erótica" da filosofia e da personagem Sócrates, cf., por exemplo, Erler (2008, p. 115-18) e Riedweg, In. Naumann (2001, p. 13-23). Encontramse observações úteis também em Taglia (1996, p. xxxix), que assinala corretamente os paralelos entre a figura socrática e as características de Eros. Também são muito importantes as considerações de Szlezák (1988, p. 335), para quem o objetivo do Banquete reside precisamente na celebração do filósofo e da personagem em que esta figura se encarna, ou seja, Sócrates. 
autossuficiência, pela consciência deste deficit, e pela tensão (epithymia) para a sua supressão.

Se um dos aspetos mais característicos dos diálogos platônicos consiste na difundida presença de afirmações de tipo metadiscursivo, muitas vezes relativas precisamente à natureza da filosofia, o que Sócrates e Diotima dizem de Eros (e depois Alcibíades diz de Sócrates) no Banquete constitui, talvez, o exemplo paradigmático deste género de comunicação de certa forma indireta. 0 Banquete, mais do que os outros diálogos, representa um logos peri philosophias, em que, de certa forma, se estabelecem a natureza, as finalidades e os limites da atividade filosófica. Estou inclinado a defender que as reflexões contidas na parte final do diálogo estão, antes de mais, relacionadas com o tema da paideia filosófica, de que apresentam dois exemplos: um coroado pelo sucesso (o da "iniciação" de Sócrates por parte de Diotima), o outro destinado ao fracasso (o da educação de Alcibíades por parte de Sócrates).

De resto, a íntima relação entre Eros e filosofia parece estar implicada na célebre afirmação de Sócrates que, suspendendo a sua costumada declaração de ignorância, afirma conhecer só ta erotiká,

11.NEm 177 D Sócrates afirma: «costumo dizer que não conheço outras coisas a não ser as do amor» (a afirmação aparece também em 193 E; 198 D; 199 B). Sobre este ponto, em especial sobre a possibilidade de conciliar esta admissão de conhecimento com a declaração socrática habitual de ignorância, Ioppolo (1999, p. 53-74), argumentou uma tese amplamente partilhável.

12. Sobre a natureza metodológica e não imediata e intuicionista da dialética (e da noesis) em Platão remeto para Ferrari (2010, p. 599-619).

13.NMas sobre a natureza mortal da mãe de Eros, Karfik (p. 154) tem algumas reservas; para ele Penia não é nem deusa, nem um ser mortal, mas uma personagem alegórica.

14.NSobre a narração mítica do nascimento de Eros, cf. Reale (1997, p. 170-78) e Sier (p. 50-8).

15. Parecem-me pois convincentes as considerações de Sier (p. 23). Sobre a possibilidade de identificar Eros com a alma, Karfik (art.

cit), passim, argumentou teses inteligentes e partilháveis. isto é, os factos de amor (177 D) ${ }^{11}$. Se, portanto, o daimon Eros e o indivíduo Sócrates são "filósofos" por excelência, o que nos diz o Banquete acerca da natureza da filosofia e da I filosófica?

3. A primeira estratégia realizada por Diotima no seu discurso sobre Eros consiste na identificação de uma condição intermédia (metaxy) entre sophia e amathìa, e doxa, mais precisamente a disposição que se tem quando se opina de modo correto (ortà doxazein). Um estado semelhante deve ser evidentemente identificado com Eros e, por conseguinte, com a filosofia. Todavia, isto não significa que a característica intermediária entre sapiência e ignorância represente uma condição insuperável, a partir do momento em que precisamente a descrição da ascensão erótica demonstra como a alma pode aceder ao conhecimento do belo em si, isto é, das ideias, logo à sabedoria. Vale a pena assinalar que Diotima adere à concepção, largamente atestada nos diálogos, segundo a qual o conhecimento se distingue da opinião reta dada a sua capacidade de dar conta de (logon dounai), ou seja, legitimar, os próprios conteúdos (202 A), quer dizer, em virtude de uma componente fundadora e justificadora de matriz claramente dialético-metodológica ${ }^{12}$. Em todo o caso, o reconhecimento por parte de Diotima de uma diferença entre philosophia e sophia não pode ser considerada um dado definitivo e insuperável, exatamente como a condição de aporia não representa um estado intransponivel, dado que a aporia prepara a euporia.

Em segundo lugar, pelas afirmações de Diotima, com base nas quais Sócrates refuta a tese de Ágaton, que estabelece na privação, ou melhor, na consciência da falta do bem e do belo, a condição de onde parte o impulso erótico e, por conseguinte, atribui a Eros a qualificação de daimon e não de deus (202 D-203 A). Portanto, a sacerdotisa começa por fornecer uma espécie de fundação mítica da natureza intermédia de Eros, explicando que o daimon nasceu de mãe mortal, Penia [= Pobreza $]^{13}$, e de um deus, Poros [= Engenho]: da mãe herdou a condição de deficit, quer dizer, de aporia, enquanto que do pai recebeu a capacidade de superar este deficit, ou seja, de alcançar a euporia (203 B-204 C) ${ }^{14} .0$ pai de Eros é descrito como corajoso (andreios) e desejoso de sabedoria (phroneseos epithymetés), isto é, em termos não diversos de como foram apresentados os filósofos na República. Dele se diz também que passa a vida a filosofar (philosophòn dia pantòs tou biou), algo que deveria induzir a defender que a condição do filósofo platônico é uma condição divina e não simplesmente humana. Em todo o caso, o estado de aporia que Eros herda da mãe deveria poder ser superado graças às qualidades filosóficas herdadas do pai. Por outras palavras, o reconhecimento da condição de falta está acompanhado da consciência de que Eros é de certa forma capaz de alcançar uma Überwindung desta endeia.

Dado que Eros é caracterizado em termos de desejo (epithymia), ele não pode deixar de dizer respeito à alma, que representa o sujeito onde se originam todos os desejos. Na verdade, a alma não é só uma entidade que possui desejos, mas é ela mesma epithymia; neste sentido Eros é para a alma não um pathos, mas sim uma hexis, isto é, uma disposição natural e duradoura ${ }^{15}$. Em todo o caso, não há dúvida de que Eros é erastés (203 C), ou 
seja, amante, e não eromenon ou erastón, isto é, amado. Os intérpretes dividem-se sobre a questão se a epithymia erótica, que para Platão está dirigida para o belo e o bem, deva ser atribuída só à parte racional, isto é, ao logistikon, como parece dever-se admitir com base na sua orientação, ou se ela se refere também às outras partes da alma, como parece, pelo contrário, poder-se concluir com base no fato de as formas inferiores do impulso erótico se dirigirem aos corpos ${ }^{16}$.

Uma das teses principais de Diotima refere-se à orientação da pulsão erótica para o bem e 0 belo (204 D-E). Como se sabe, a formulação desta tese deu origem a numerosas divergências entre os intérpretes. Mas não há dúvida de que a identificação do que a sacerdotisa tem em mente quando fala de agathon deveria ser isenta de disputas, pois diz explicitamente que o bem para o qual Eros tende constitui-se pela eudaimonia, ou melhor pelo ser eudaímon, que ocupa a posição de telos de cada forma de volição (205 A). A colocação do fim na eudaimonia não diz ainda nada sobre a natureza desta eudaimonia, mas estabelece um princípio de natureza formal, que se refere à estrutura da nossa volição. A admissão desta ou de outra concepção da eudaimonia diz respeito, pelo contrário, à esfera da ética e pode ser deixada de lado neste contributo.

Agora Diotima pode formular a sua tese principal em torno de Eros. A sacerdotisa chega a ela por meio de uma análise da fenomenologia do impulso erótico, que a conduz à afirmação de que Eros consiste na gennesis e no tokos en kaló, isto é, na geração e no parto no belo (206 C-E $)^{17}$. Isto implica evidentemente que Eros represente uma $I$ e que a esfera na qual se dá esta poiesis seja constituída pelo belo. 0 fim desta geração consiste, segundo a sacerdotisa, na imortalidade, ou melhor, na posse duradoura, imortal, do bem, dado que Eros deseja athanasia meta agathou ${ }^{18}$, isto é, a imortalidade conjunta com o bem (207 A). 0 desejo de imortalidade exprime-se de diversas formas e pode ser quer de natureza física quer intelectual: no primeiro caso ele concretiza-se na geração sexual, que garante a imortalidade da espécie (207 A-208 B), no segundo realiza-se através da produção de raciocínios em torno da virtude (logoi peri aretes) e do modo como um homem deve ser bom, ou seja, por meio da prática da paideia (209 B-C).

Portanto, para Diotima a geração por obra de Eros na esfera da alma realiza-se dentro do processo educativo e requer a presença de jovens belos, isto é, dotados de qualidades intelectuais, que possam, se corretamente orientados, realizar aquele processo de eternização do saber e do conhecimento que permite aceder à única forma de imortalidade permitida ao homem. De resto, muitos diálogos, começando pelos da juventude (o caso do Cármides é emblemático) e acabando no Teeteto, põem em cena a procura de belos jovens por parte do filósofo Sócrates, com os quais pode instaurar o processo educativo de que depende a perpetuação do saber ${ }^{19}$. As palavras de Diotima concordam muito bem com o que se lê no Fedro a propósito da capacidade do dialético escolher uma alma idônea (psyche prosekousa) e nela semear raciocínios (logoi) capazes de crescer por si e de gerar outros raciocínios (Phdr. 276 E-277A).

A paideia representa pois um momento central da prática filosófica, porque é o instrumento fundamental com o qual o filósofo pode iniciar o processo de transmissão do saber por meio do qual se realiza o desejo de imortalidade.

4. 0 discurso de Diotima atinge o seu auge com a célebre descrição da scala amoris, ou seja, com a autêntica "iniciação" nos mistérios do amor, que consiste na apresentação dos diversos graus através dos quais se exterioriza o impulso erótico (209 E-212 A). Trata-se da sequência dos objetos para os quais se dirige Eros, que inicialmente se dirige para a beleza de um corpo, para depois abraçar a unidade e a identidade (hen kai tautòn) da beleza dos corpos; sucessivamente (meta tauta) deveria orientar-se para a beleza dos produtos da alma, que representa algo de "maior valor" (timioteron) em relação à beleza física; no âmbito da esfera da alma o impulso erótico tem por objeto as instituições e as leis (epitedeumata kai nomoi), e sucessivamente os conhecimentos científicos (epistemai), ou seja, presumivelmente os conhecimentos de caráter matemático; neste nível a atividade de Eros gera aquele tipo de raciocínios (logoi) nos quais se realiza a paideia filosófica (210 D); o passo seguinte, que representa o auge e o fim (telos) de toda a ascensão
16. A primeira opção é tomada por Kahn (p. 258-61), enquanto que a favor da segunda argumenta Sier (p. 28-30).

17. Sobre Eros como tokos en kaló, cf. Rowe (1998, p. 45-7) e Chang (p. 432-34)

18. Sobre o desejo de possuir sempre o bem, cf. Ferrari, In. Kraut (1992, p. 248-76, espec. 254-55). Vale a pena assinalar que também no final do Timeu se estabelece uma ligação íntima entre eudaimonia e athanasia no âmbito da concepção do telos do homem (90 B-C). Cf. a propósito as brithantes observações de Sier (p. 182-83).

19. 0 tema da busca "filosófica" da imortalidade através da educação dos jovens dotados foi analisado a fundo por Centrone ( $p$. 43), o qual nota que «o filósofo... pretende tornar imortal o saber que obteve, não só mantendo-o sempre vivo dentro da sua alma, mas também semeando-o e fazendo-o crescer noutras almas, garantindo assim a conservação». 
20. Sobre o tipo de teleologi implicada na ascensão erótica descrita por Diotima encontram-se notações importantes em Payn (2008, p. 123-45)

21. Sobre este aspecto, ou seja, sobre o facto de na ideia do belo «das Schönsein selbst nicht au Faktoren des Trägers beruht», Sie (p. 155)

22. Um quadro exaustivo encontra-se, por exemplo, em Sier (pp. 145-97), para o qual se remete também para a indicação da literatura crítica. Pontos de reflexão interessantes encontramse também em Barbaric, In Havlicek \& Cajthaml (p. 210-29).

23. Sobre o fracasso de Sócrates como mestre, veja-se Gagari (1977, p. 22-37). Tende, pelo contrário, a atenuar o fracasso de Sócrates como professor educador (JIRSA, In. Havlicek \& Cajthaml, p. 280-92)

24. Sobre a característica "inurbana" da entrada em casa de Ágaton por parte de Alcibíades, descrita como uma espécie de Dioniso redivivus, cf. Eming (2006, p. 127-59)

25. Sobre a incapacidade de Alcibíades de resistir à atração do poder e do sucesso, cf. Prior In. McPherran, 1997 (p. 109-23, espec. 118)

26. Também Szlezák (p. 346-48) chama a atenção para o fato de Alcibíades ser o único dos presentes a não ter sido iniciado por Diotima, por não ter ouvido o discurso. erótica ${ }^{20}$, constitui-se pela "visão" da ideia do belo, isto é, de um tipo de beleza que já não é, como nos estádios anteriores, a beleza de algo (corpo, instituição, conhecimento), mas o belo em si mesmo, independente de qualquer "portador" (Träger), ou seja, de qualquer participante ${ }^{21}$.

Aqui não é possivel tocar os inúmeros problemas, de caráter epistemológico e metafísico, implicados neste texto ${ }^{22}$. Limitamo-nos a constatar que a scala amoris de Diotima implica a admissão de uma Rangordnung ontológica, ordenada pela sequência corpo-alma-ideia (diz-se da alma que é de classe superior, timioteron, relativamente ao corpo, enquanto que termo ephexés, em $210 \mathrm{E}$, implica precisamente uma sucessão ordenada de níveis), e a prescrição de um procedimento ascensional ao qual não parecem alheios preceitos metodológicos (o advérbio orthós aparece em 210 A 2, 4, 6, E 3, 211 B 5), ambos motivos perfeitamente inseríveis no âmbito da filosofia platónica.

0 discurso de Diotima parece então conter os delineamentos gerais da erótica platônica. Além disso é apresentado em forma de diálogo com um jovem discípulo, particularmente dotado e prometedor, Sócrates, que se demonstra capaz de apreender o ensinamento da sacerdotisa e de alguma forma eternizá-lo, quer dizer, torná-lo imortal.

5. Se o ensinamento de Diotima a Sócrates parece coroado de sucesso, o de Sócrates a Alcibíades conclui-se com um fracasso, apesar das qualidades do jovem e brilhante discípulo. Por quê? Quais são as razões que determinam o insucesso de Sócrates como mestre e como dialético e de Alcibíades como discípulo? ${ }^{23}$

Alcibíades ${ }^{24}$ parece estar em posse de muitas das qualidades que deveriam conduzi-lo, se orientado corretamente, à virtude e por conseguinte à eudaimonia, e ainda assim ele se perde pelo caminho, e o seu fracasso parece até representar a falsificação real da ética socrática, dado que Alcibíades reconhece a superioridade do ensinamento de Sócrates, apesar de se deixar vencer pelo desejo das honras que são oferecidas pelo povo, isto é, pelo sucesso no campo da política, deixando assim entender que o conhecimento do bem não é condição suficiente para a aquisição da virtude se não for acompanhado por uma adequada volição e autocontrole (enkrateia): «tenho consciência (synoida) de não me poder opor (antilegein) ao dever de cumprir o que ele me manda fazer, mas por outro lado, quando me aparto dele, sou tomado pelo desejo de honras proporcionadas pela multidão» $(216 \mathrm{~B}-\mathrm{C})^{25}$.

Alcibíades teve o melhor educador possível, o próprio Sócrates. Então porque não seguiu a via da virtude e da felicidade? 0 que the faltou? 0 deficit de Alcibíades é essencialmente de natureza epistémica, como Platão sugere também através do artifício dramático da sua entrada em cena, no fim do banquete, quando todos os outros discursos já foram pronunciados. Ele é pois a única personagem do diálogo a não ter ouvido o discurso de Diotima narrado por Sócrates e, por conseguinte, a desconhecer os “mistérios do amor". Em especial, Alcibíades ignora a sequência dos graus da iniciação erótica descrita na scala amoris; ele não sabe que a beleza do corpo, e em particular a de um só corpo, é verdadeiramente pouca coisa em relação à beleza da alma e que ela é, por sua vez, inferior em relação ao belo em si.

Desconhecendo tudo isto, Alcibíades dirige a sua atenção só para corpos e indivíduos, Ágaton e sobretudo Sócrates. Como observou Martha Nussbaum, ele faz parte dos que não estão ainda "reformados" (1996, p. 335) ${ }^{26}$, que se aproximam de Sócrates com base numa pulsão emotiva e sem uma adequada preparação teórica. A marca que caracteriza a sua relação com Sócrates é a da emotividade e do tumulto interior (por exemplo $215 \mathrm{D}-\mathrm{E}$ ), que podem ter sentido somente nos estádios inferiores da ascensão erótica. Ele confunde a enktrateia de Sócrates com a soberba (215 B, 219 C). A sua absoluta ignorância dos fundamentos metafísicos da erótica platónica manifesta-se de maneira evidente quando pretende trocar a própria beleza física pela beleza améchanon que Sócrates possui, ou seja, ceder a opinião e receber em troca a verdade (anti doxes aletheia: 218 E-219 A). Mas uma pretensão deste género comporta evidentemente a ignorância da escala ontológica exposta por Diotima, quer dizer, implica a remoção da concepção das ideias, em que culminam os grandes mistérios de Eros.

Certamente Alcibíades demonstra ter entendido uma característica fundamental da personagem 
Sócrates e do seu ensinamento, ou seja, a distinção entre a exterioridade e a interioridade dos logoi ${ }^{27}$. Ele sabe bem que os discursos de Sócrates, tal como as estátuas dos Silenos que contêm no seu interior simulacros de deuses, exteriormente parecem quase banais, mas escondem no seu interior agalmata tes aretes, isto é, imagens de virtude e são capazes de conduzir quem os compreende ao bem. Todavia ele demonstra não ser capaz de "abrir" estes logoi porque desconhece os fundamentos filosóficos que permitiriam esta "abertura". Quem teorizou o princípio hermenêutico da "abertura" imanente dos logoi socráticos revela-se incapaz de operar esta abertura, e a causa deste fracasso reside exatamente no fato de que o princípio da abertura imanente é parcial $^{28}$. A abertura deve ser acompanhada da posse de teoremas filosóficos específicos, ou seja, das conceções expostas por Diotima, e em primeiro lugar pela teoria da gradação ontológica dos objetos de Eros. Só o recurso a estes teoremas, que assumem o lugar de autênticos timiotera, que apenas o dialético possui, permitiria a Alcibíades evitar a confusão que o induziu a propor a Sócrates trocar a beleza corpórea pela autêntica.

6. A última parte do Banquete, com os discursos de Diotima e Alcibíades, pode também ser lida como o confronto entre duas tentativas de paideia, uma, a de Diotima dirigida a Sócrates, coroada de sucesso, a outra, a de Sócrates dirigida a Alcibíades, marcada pelo fracasso. Sócrates está envolvido em ambos os processos: no primeiro como discípulo, no segundo como mestre. A educação nos mistérios de amor descrita por Diotima, mesmo começando por formas de Eros potencialmente de caráter simétrico e recíproco, culmina numa relação assimétrica, a do iniciado com o belo em si. Vice-versa, o Eros desejado por Alcibíades mostra-se um Eros recíproco (semelhante àquele descrito no mito de Aristófanes), precisamente porque é incapaz de elevar-se acima da esfera individual e particular ${ }^{29}$.

A falta de posse dos teoremas "eróticos" de Diotima e em especial da Rangordung des Seienden por parte de Alcibíades é a razão principal do seu fracasso, da sua incapacidade de realizar uma abertura autêntica dos logoi socráticos. Se o Eros é filósofo e se a filosofia é essencialmente erótica, Eros e filosofia não podem passar sem a apropriação daquela gradação ontológico-valorativa que representa um dos núcleos teóricos do pensamento platônico.

Tradução de Maria da Graça Gomes de Pina

\section{REFERÊNCIAS BIBLIOGRÁFICAS}

BARBARIC, D. (2007) Die Stufen der Zeitlichkeit. Zu Diotimas Rede in Platons ,Symposion', In. A. Havlicek - M. Cajthaml (ed.), Plato's 'Symposium', Prague.

CENTRONE, B. (2009). Il problema della reciprocità nell'eros platonico, In. Metamorphoses of Love, «Theoria» V. 29, p. 33-49.

CHANG, R.-C. (2002). "Plato's Form of the Beautiful in the 'Symposium' versus Aristotle's Unmoved Mover in the 'Metaphysics' Lambda", «Classical Quarterly» V. 52, p. 431-46.

DIXSAUT, M. (20030 La natura filosofica. Saggio sui dialoghi di Platone. Napoli.

EMING, K. (2006) Tumult und Erfahrung. Platon über die Natur unserer Emotionen. Heidelberg.

ERLER, M. (2008) Platone. Un'introduzione. Torino.

FERRARI, F. (2002) L'oikeion dell'anima e la conoscenza filosofica: il motivo gnoseologico nel 'Liside'. In. L. TorRaCA (a cura), Scritti in onore di Italo Gallo. Napoli.

- (2010). Dalla verità alla certezza. La fondazione dialettica del sapere nella 'Repubblica' di Platone, «Giornale Critico della Filosofia Italiana» V. 89, p. 599-619.

(1992) Platonic Love, In. R. Kraut (ed.), The Cambridge Companion to Plato. Cambridge.

GAGARIN, M. (1997). "Socrates' hybris and Alcibiades" failure", «Phoenix» V. 31, p. 22-37.

GAISER, K. (1984) Platone come scrittore filosofico. Saggio sull'ermeneutica dei dialoghi di Platone. Napoli.

IOPPOLO, A. M. (1999). Socrate e la conoscenza delle cose d'amore. «Elenchos» V. 20, p. 53-74.

JIRSA, J. (2007) Alcibiades' Speech in the 'Symposium' and its Origins, In. A. Havlicek - M. Cалthaml (ed.), Plato's 'Symposium', Prague.

KAHN, C. (2008) Platone e il dialogo socratico. L'uso filosofico di una forma letteraria. Milano, 2008.

KARFIK, F. (2007) Éros et l'âme, In. A. Havlicek - M. CajthamL (eds.), Plato's 'Symposium'. Prague.

NUSSBAUM, M. (1996) La fragilità del Bene. Fortuna ed etica nella tragedia e nella filosofia greca. Bologna.

PAYNE, A. (2008). “The Teleology of the Ascent in Plato's 'Symposium'". «Apeiron» V. 41, p. 123-45.
27. Sobre este tema são sempre estimulantes as páginas de Gaiser (1984).

28. Tudo isto é explicado na melhor das formas por Szlezák ( $p$. 350-51, nota 49), que observa precisamente que a abertura «não é possivel de modo interno», ou seja, imanente: «como o discurso de Diotima é diferente do de Alcibíades, então é necessário o Ménon e a República para abrir alguns dos enigmas do Eutidemo».

29. Nussbaum (p. 363) chega a dizer que «a história de Alcibíades, de facto, é só uma história de amor... Alcibíades, quando tem de falar do eros, fala de uma pessoa». 
PRIOR, W. J. (1997). “Did Plato Write Socratic Dialogues?”, In. Wisdom Ignorance and Virtus. New Essays in Socratic Studies, «Apeiron», V. 30 N. 4, p. 109-23.

REALE, G. (1997) Eros demone mediatore. Il gioco delle maschere nel 'Simposio' di Platone. Milano.

RIEDWEG, C. (2001) Verführung zum Denken. Sokrates als Erotiker. In. B. Naumann (Hg.), Verführung / Seduction, Wien.

ROBINSON, T. M. (2007) Ficino's 'Symposium', In. A. Havlicek, A. \& Cajthaml, M. (eds.). Plato's 'Symposium'. Proceedings of the Fifth Symposium Platonicum Pragense, Prague.
ROWE, C. (1998) Il ,Simposio' di Platone, a cura di M. Migliori, Sankt Augustin.

SIER, K. (1997) Die Rede der Diotima. Untersuchungen zum platonischen 'Symposium'. Stuttgart:Leipzig.

SZLEZÁK, T. A. (1988) Platone e la scrittura della filosofia. Milano.

TAGLIA, A. (1996) Platone, Simposio. Roma-Bari.

VLASTOS, Gregory. (1973) The Individual as an object of Love in Plato, agora em Platonic Studies, Princeton.

WILAMOWITZ, U. Von. (1919) "Das Gute an sich, Platons Gott, liebt freilich nicht wieder", In. Platon. , Bd. 1: Berlin.

Recebido em fevereiro de 2012. Aprovado em maio de 2012. 